\title{
ELEMENTUM - LÚDICO COMO FERRAMENTA FACILITADORA DO PROCESSO DE ENSINO-APRENDIZAGEM SOBRE TABELA PERIÓDICA
}

\author{
I. A. M. PINHEIRO, A. D. M. SOUZA, E. F. MOREIRA, L. M. BERTINI, P. R. N.FERNANDES e L. A. ALVES* \\ Instituto Federal de Educação, Ciência e Tecnologia do Rio Grande do Norte \\ leonardo.alcantara@ifrn.edu.br*
}

Artigo submetido em novembro/2015 e aceito em dezembro/2015

DOI: $10.15628 /$ holos.2015.3647

\section{RESUMO}

No presente estudo buscou-se incentivar o uso de jogos lúdicos para o ensino de química, bem como, introduzir na educação o jogo Elementum como meio facilitador do processo de ensino-aprendizagem sobre a tabela periódica. Por meio dos questionários aplicados após o jogo, obteve-se um diagnóstico comprovando que o uso de jogos lúdicos, em especial o Elementum, foi um grande incentivo para a aprendizagem dos alunos. Notando-se então, uma aprendizagem de forma satisfatória e mais espontânea dos mesmos.

PALAVRAS-CHAVE: Elementum, Tabela periódica, Lúdico, Jogos no Ensino de Química.

\section{ELEMENTUM - LUDIC AS A TOOL FACILITATOR IN THE TEACHING-LEARNING PROCESS OF PERIODIC TABLE}

\begin{abstract}
In the present study we sought to encourage the use of fun games for chemistry teaching and to introduce the educational Elementum game as a facilitator in the teaching-learning process about the periodic table. Through questionnaires applied after the game had
\end{abstract}

become a diagnosis showing that the use of fun games, especially Elementum, is a great incentive for student learning. Noting then a learning satisfactorily and more spontaneousthereof.

KEYWORDS: Elementum, Periodic table, games, Chemistry Teaching . 


\section{INTRODUÇÃO}

Muitos professores, atualmente, enfrentam grande dificuldade ao tentar desmistificar a visão tradicional sobre a Química e, deste modo, tornar a disciplina mais agradável para os alunos. A maneira mais utilizada para que se possa obter sucesso nesse processo é o auxílio dos diversos recursos pedagógicos como, por exemplo, o uso dos jogos didáticos e outros tipos de atividades lúdicas.

O atual ensino de Química, com seu extenso programa para a educação básica, parece ser inadequado em sua forma, uma vez que passa a ilusão de um conhecimento absoluto e imutável da química. Deste modo, acaba por não mostrar a relatividade dos fatos e a correlação entre eles e nosso cotidiano (NASCIMENTO, 2007).

Nesse contexto, a utilização de jogos é indicada como um tipo de recurso didático educativo que pode ser utilizado em momentos distintos. O que envolve uma série de fatores, tais como: a apresentação de um conteúdo, ilustração de aspectos relevantes ao conteúdo, a revisão ou síntese de conceitos importantes e avaliação de conteúdos já desenvolvidos (CUNHA; 2004). Por meio destes, ocorre a construção de diversos conhecimentos, sendo eles cognitivo, físico, social e psicomotor o que o leva a memorizar mais facilmente o assunto abordado. Assim, a atividade lúdica objetiva, principalmente, propiciar o meio para que o aluno induza o seu raciocínio, ou seja, ele próprio vai refletir e consequentemente construir o seu conhecimento (MELO, 2005).

Com isto, o presente artigo expõe a utilização do jogo Elementum como ferramenta para auxiliar o processo ensino-aprendizagem sobre Tabela Periódica, tornando este mais acessível e fazendo com os alunos pensem no assunto de forma diferenciada.

\section{REVISÃO BIBLIOGRÁFICA}

\subsection{Uso de jogos no ensino}

O ensino deve ser cada vez mais dinamizado, visto que, aulas diferenciadas promovem uma maior interação, desenvolvimento ao mesmo tempo em que o processo de ensino-aprendizagem é facilitado.

Essa proposta de utilizar jogos lúdicos como novos meios de ensinar é o que faz com que a educação evolua. Russel (1999), em extensa revisão bibliográfica, descreve artigos que utilizam jogos para ensinar nomenclatura, fórmulas e equações químicas, conceitos gerais em Química (massa, propriedades da matéria, elementos químicos e estrutura atômica, soluções e solubilidade), Química Orgânica e Instrumentação.

“Primeira das características fundamentais do jogo: o fato de ser livre, de ser ele
próprio liberdade. Segunda característica, intimamente ligada à primeira: o jogo
não é vida 'corrente' nem vida 'real'. Pelo contrário, trata-se de uma evasão da
vida 'real' para uma esfera temporária de atividade com orientação própria. Reina
dentro do domínio do jogo uma ordem específica e absoluta. E aqui chegamos a
sua outra característica, mais positiva ainda: ele cria ordem e é ordem. [...] O jogo
lança sobre nós um feitiço: é fascinante, cativante. Está cheio das duas qualidades 
mais nobres que somos capazes de ver nas coisas: o ritmo e a harmonia" (HUIZINGA, p. 11, 1971).

Deste modo é visível a importância do lúdico (jogos) no Ensino de Ciências e, particularmente, de Química.

Vygotsky (1991), em seus diversos trabalhos, buscou analisar tanto o papel do desenvolvimento das crianças quanto das experiências sociais e culturais por meio do estudo do jogo na criança. O mesmo buscou discutir qual o real papel do "brincar", tendo deste modo, os jogos incluídos. Para ele, também é de extrema importância a interdependência dos sujeitos durante o jogo, pois jogar é um processo social. A partir desse contexto, Gazola (2010) constata a necessidade e a importância da aplicação de atividades lúdicas na disciplina de Química.

Vale ressaltar que um jogo não deve ter apenas a função lúdica, do brincar, se divertir, deve ser ao mesmo tempo educativo. Para Kishimoto (1996), função educativa está ligada a como o aluno apreende conhecimentos, e habilidades, já a função lúdica está relacionada ao caráter de diversão e prazer que um jogo propicia.

Ainda citando Vygotsky (1989), "os jogos estimulam a curiosidade, a iniciativa e a autoconfiança; aprimorando o desenvolvimento de habilidades linguísticas, mentais e de concentração e exercitam interações sociais e trabalho em equipe".

Do ponto de vista docente, faz-se necessário utilizar-se deste recurso didático, que são os jogos. A partir deste pressuposto foi desenvolvido um jogo chamado Elementum com cartas tendo como tema central a Tabela Periódica dos elementos químicos, promovendo, assim, uma abordagem diferente do assunto aos alunos do Ensino Médio e Fundamental.

\subsection{Jogos no ensino de Química}

É constante e contínuo os estudos que mostram que o ensino de Química é, em sua maioria, tradicional. O mesmo se apresenta desprovido de contextualização e visando apenas a memorização dos conteúdos, os afastando da realidade e do dia-a-dia dos discentes. Para Piaget (1978), as origens das manifestações lúdicas acompanham o desenvolvimento da inteligência vinculando-se aos estágios do desenvolvimento cognitivo. Desse modo, todos os assuntos de Química podem ser abordados em sala de aula não apenas de uma forma teórica, mas também de forma prática e bem contextualizada, buscando mexer com o cognitivo do aluno.

Em seu estudo, Soares (2008) faz um breve levantamento a respeito dos jogos para o ensino e, na tentativa de delimitar esse conceito, sugere que a utilização do jogo faz entrar em um campo repleto de definições e de entendimentos em diferentes esferas da sociedade. Assim, compartilhando de suas conclusões, considera-se o jogo como o resultado:

“[...] de interações linguísticas diversas em termos de características e ações lúdicas, ou seja, atividades lúdicas que implicam no prazer, no divertimento, na liberdade e na voluntariedade, que contenham um sistema de regras claras e explícitas e que tenham um lugar delimitado onde possa agir: um espaço ou um brinquedo."

Além disso, quando o estudo da Química permite que os alunos desenvolvam uma visão crítica do mundo que os cerca, o interesse pelo assunto aumenta. Situações relacionadas a 
problemas sociais e ambientais do meio em que estes estão inseridos geram condições de percebêlos e discuti-los, contribuindo para a possível intervenção e resolução dos mesmos (SANTANA; 2006).

Cabe ao professor a análise e avaliação dos jogos, visando a sua potencialidade para a educação, atribuindo, deste modo, um valor pedagógico para os jogos.

\section{METODOLOGIA}

A criação do jogo Elementum teve como objetivo introduzir em sala de aula uma atividade lúdica para o ensino de tabela periódica de forma a auxiliar o processo ensino-aprendizagem do assunto em questão. Esta foi produzida com parâmetros semelhantes ao Jogo de cartas denominado Uno ${ }^{\circledR}$.

Para aplicação do jogo, uma turma de 20 ano da Escola Estadual Professor Antônio Dantas, no município de Apodi - RN. Esta foi separada em 4 equipes com 7 integrantes cada e, para que se desse início ao jogo, cada equipe teve que escolher um representante primário. Um dos representantes de qualquer uma das equipes misturou as cartas e distribuiu-as, de modo que cada jogador tenha ficado com 9 cartas.

A primeira rodada, no sentido horário, consistiu em cada representante pegar uma carta e, aquele que saísse com a carta de maior número atômico, iniciava o jogo. Deste modo, a carta de maior número atômico foi a carta de largada para o jogo. Caso o representante jogasse uma carta "pergunta", todos teriam que pôr a mão sobre a carta, o último a pôr a mão teria que responder uma pergunta em $1 / 2$ minuto com direito a pesquisa, caso errasse seria substituído. Exemplo da carta "pergunta" na Figura 1, abaixo.

\section{PERGUNTA? \\ 1-Qual o nome do cientista que desenvolveu a maneira de organizar os elementos químicos que ainda é utilizado até hoje? \\ a) Dalton \\ b) John Newlands $\quad$ c) Dmitri Mendeleev d) Henry Monseley}

Figura 1: Carta "pergunta" (frente e verso)

No jogo haviam outros tipos de cartas especiais, o que o tornava mais próximo do jogo padrão. Um exemplo é a carta de "substituição" que servia para substituir/alternar o jogador atual por outro membro da equipe. Se a carta fosse uma do tipo "desafio", a equipe deveria cumprir com uma tarefa proposta. Caso o desafio não fosse cumprido o jogo do representante era completamente substituído, dando-lhe 9 novas cartas do monte. A carta chamada "pular" fazia com que o jogador seguinte perdesse a vez de jogar por uma rodada. A carta "reverte" deslocava o jogo no sentido contrário ao que já estivesse como pode-se ver os exemplos das cartas na Figura 2 abaixo.

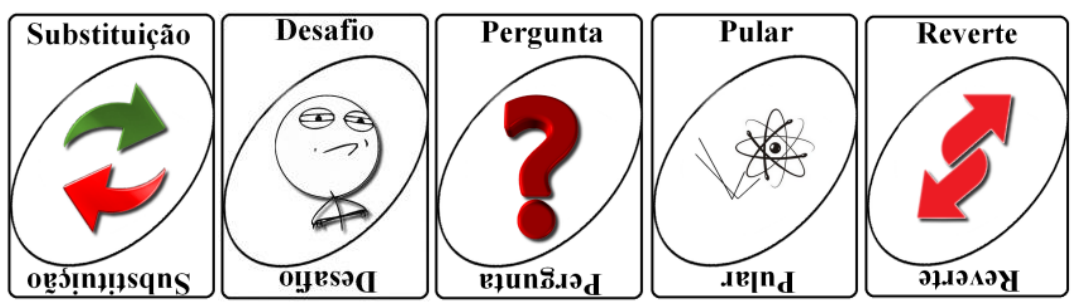

Figura 2: Cartas especiais 
Após a aplicação do jogo foi realizado a verificação da aprendizagem, sendo esta a última etapa da atividade, caracterizada pela entrega de fichas de avaliação aos alunos contendo afirmações a respeito da atividade desenvolvida.

\section{RESULTADOS E DISCUSSÕES}

Os alunos demonstraram-se muito interessados pela atividade desenvolvida, de modo que houve grande participação de todos em diferentes grupos. Alguns momentos da aplicação do jogo podem ser verificados a partir dos registros apresentados na Figura 3, a seguir.

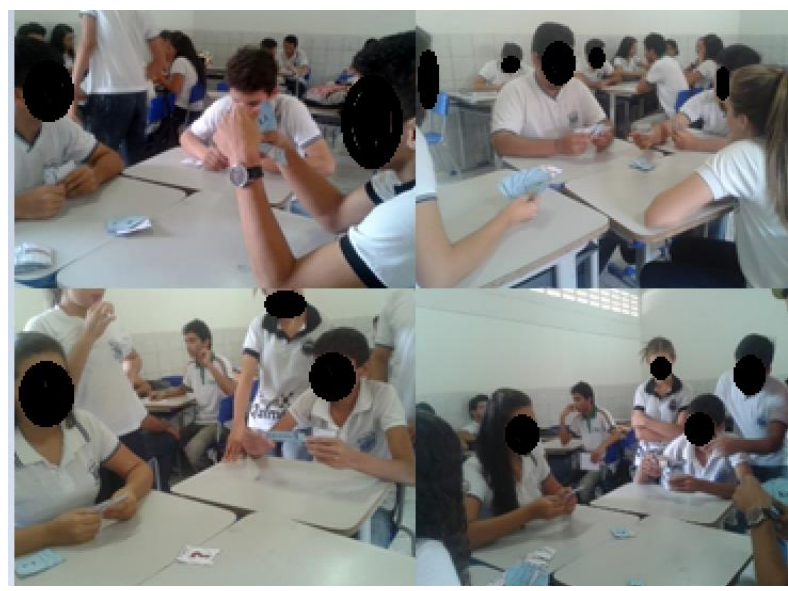

Figura 3: Fotografia dos discentes durante aplicação do jogo Elementum Fonte: Fotografias tiradas pelos próprios autores

Após a aplicação do jogo, um questionário foi aplicado e, a partir do levantamento dos dados obtidos, um gráfico em percentual foi montado para análise. Esta avaliação foi realizada utilizando de afirmativas onde cada respondente tinha, como opção: Concordo, concordo parcialmente e discordo. Este tipo de questionário trabalha de modo que o aluno não é induzido a uma resposta pronta. As afirmativas são expostas de forma impessoal sobre a aplicação da atividade (ANEXO I).

Na primeira afirmativa, os alunos foram solicitados a se posicionar se houve algo no jogo que prendeu a atenção deles e $67 \%$ concordaram com esta afirmativa havendo, deste modo, uma maior desenvoltura no jogo, tal desenvoltura os possibilitava criar estratégias de jogo, já que, os mesmos estavam entendendo o assunto. A segunda afirmativa buscava observar se os mesmos, ao passar as etapas do jogo, se sentiram mais confiantes e, de forma positiva $70 \%$ concordaram isso os induzia a permanecer dentro da atividade. A autoconfiança é um ponto essencial em todas as disciplinas, já que o aluno necessita acreditar no que aprendeu para que possa expor respostas a possíveis questionamentos.

A terceira afirmativa era em relação se as constantes mudanças no jogo os ajudaram a manter a atenção. Neste ponto, $89 \%$ dos alunos concordaram. Isto mostra que os mesmos, ao ficarem atentos deviam utilizar mais o raciocínio lógico no jogo em si.

A quarta afirmativa estava relacionada com a satisfação dos respondentes quanto ao jogo e se teriam a oportunidade de utilizar, futuramente, o que eles aprenderem no jogo. $74 \%$ dos alunos concordaram, e esta afirmativa serve para mostrar que o jogo não utiliza-se apenas da parte lúdica, ou seja, da brincadeira, mas desenvolve competências maiores para compreender e utilizar 
melhor o assunto nele introduzido. A utilização de jogos segue essa linha tênue entre o "brincar" e o "estar aprendendo", saber dosar estes pontos é essencial.

Já a quinta afirmativa envolvia o fato de, se o jogo correlacionava uma atividade de cooperação ou competição e, a maioria dos alunos concordou (70\% dos respondentes), o que tornava o jogo um meio de uni-los, ao mesmo tempo em que competiam entre si.

A sexta afirmativa avaliada consistia em saber se o jogo Elementum era de fácil aplicação e entendimento e $89 \%$ dos alunos concordaram que ele era de bom entendimento e execução.

O sétimo ponto avaliado era se os alunos alcançaram os objetivos do jogo por meio de habilidades próprias, fossem elas agilidade ou cooperação e, a maior parte deles, 78\%, concordaram que alcançaram sim os objetivos a partir da aplicação do que já haviam estudado.

Em um último quesito avaliado, verificou-se se os alunos obtiveram sentimentos positivos de eficiência ao andamento do jogo e quase por unanimidade, com $96 \%$ dos alunos, a resposta foi "concordo".

\section{CONCLUSÃO}

De acordo com o jogo Elementum desenvolvido em uma turma de 20 ano na Escola Estadual Professor Antônio Dantas, que é auxiliada pelo Programa Institucional de Bolsas de Iniciação à Docência, o Elementum foi de grande contribuição para a construção e até mesmo fixação do conteúdo tabela periódica. Concluímos, portanto, que foi de grande importância para os alunos, que puderam por meio dele desenvolver habilidades já existentes, auxiliando ainda para uma aprendizagem mais cooperativa e de forma divertida.

\section{AGRADECIMENTOS}

Os autores agradecem à CAPES pela disponibilidade das bolsas PIBID e à gestão da Escola Estadual prof. Antônio Dantas.

\section{REFERÊNCIAS}

1. CUNHA, M. B. Jogos de Química: Desenvolvendo habilidades e socializando o grupo. Eneq 0282004.

2. GAZOLA, M. B. A. A percepção da importância do lúdico na docência de química no ensino médio. Trabalho de Conclusão de Curso (Licenciatura em Química), Universidade Tecnológica Federal do Paraná, Pato Branco, 2010.

3. HUIZINGA, Johan. Homo ludens: o jôgo como elemento da cultura. São Paulo: Perspectiva, 1971.

4. KISHIMOTO, T.M. O jogo e a educação infantil. In: Jogo, brinquedo, brincadeira e educação. São Paulo: Cortez, 1996.

5. MELO, C. M. R. As atividades lúdicas são fundamentais para subsidiar ao processo de construção do conhecimento. Información Filosófica. v.2 n1, p.120 - 140, 2005.

6. NASCIMENTO, T. L.; RICARTE, M. C. C.; RIBEIRO S. M. S. Repensando o Ensino de Química 
Orgânica a nível médio. 47으 Congresso Brasileiro de Química. Área: Ensino de Química, 2007.

7. PIAGET, J. A formação do símbolo na criança: imitação, jogo e sonho, imagem e representação. 3ed. Rio de Janeiro: Zahar Editores, 1978.

8. RUSSEL, L. J. V. Using games to teach chemistry- an annotated bibliography. Journal of Chemical Education, v.76, n.4, p.481, 1999.

9. SANTANA, E.M. - A Influência de atividades lúdicas na aprendizagem de conceitos químicos. Universidade de São Paulo, Instituto de Física - Programa de Pós Graduação Interunidades em Ensino de Ciências - 2006.

10. SOARES, M.H.F.B. Jogos para o ensino de química: teoria, métodos e aplicações. Guarapari: Ex Libris, 2008.

11. VYGOTSKY, L.S. A formação social da mente. São Paulo: Martins Fontes, 1989.

12. ـ . O papel do brinquedo no desenvolvimento. A formação social da mente. São Paulo: Martins Fontes, 1991.

\section{ANEXO I - QUESTIONÁRIO DE AVALIAÇÃO DA ATIVIDADE LÚDICA ELEMENTUM}

\section{QUESTIONÁRIO AVALIATIVO - ELEMENTUM}

1. Houve algo interessante no início do jogo que capturou minha atenção.
( ) Concordo
( ) Concordo parcialmente
( ) Discordo

2. Ao passar pelas etapas do jogo senti confiança de que realmente havia aprendido.
( ) Concordo
( ) Concordo parcialmente
( ) Discordo

3. As constantes mudanças de jogador (de forma, conteúdo ou de atividades) ajudou a me manter atento ao jogo.
( ) Concordo
( ) Concordo parcialmente
( ) Discordo

4. Estou satisfeito porque sei que terei oportunidades de utilizar na prática coisas que aprendi com o jogo, assim como nele utilizei coisas que já aprendi.
( ) Concordo
( ) Concordo parcialmente
( ) Discordo

5. 0 jogo promove momentos de cooperação e/ou competição entre as pessoas que participam.
( ) Concordo
( ) Concordo parcialmente
( ) Discordo

6. Este jogo é adequadamente ligado a tabela periódica, nem é muito fácil, nem muito difícil.
( ) Concordo
( ) Concordo parcialmente
( ) Discordo

7. Consegui atingir os objetivos do jogo por meio das minhas habilidades.
( ) Concordo
( ) Concordo parcialmente
( ) Discordo

8. Tive sentimentos positivos de eficiência no desenrolar do jogo.
( ) Concordo
( ) Concordo parcialmente
( ) Discordo 